\title{
Análise médico-legal das demandas judiciais em imaginologia*
}

\author{
Medico-legal analysis of lawsuits in medical imaging \\ Luiz Carlos Leal Prestes Jr$^{1}$, Euderson Kang Tourinho², Mary Rangel ${ }^{3}$
}

Prestes L, Tourinho E, Rangel M. Análise médico-legal das demandas judiciais em imaginologia. Radiol Bras. 2012 Mar/Abr;45(2): 98-100.

\section{INTRODUÇÃO}

Em nosso país, valendo-se do chamado estado democrático de direito, criou-se, na sociedade, um falso e nocivo entendimento de que, nas relações de consumo, basta o consumidor exigir, que será prontamente atendido.

A Constituição de 1988 instituiu o habeas data, que assegura a qualquer cidadão obter informações existentes sobre a sua pessoa, em qualquer lugar, incluindo, naturalmente, o prontuário médico. Juntamente com o Código de Defesa do Consumidor, que estabelece o dever de informar por parte do fornecedor de produtos ou serviços, fez aflorar ao cidadão a necessidade de ser esclarecido sobre todos os procedimentos médicos a que irá ser submetido.

Existe um certo preconceito que todo resultado atípico e indesejado, no exercício da medicina, deva ser de responsabilidade do médico ${ }^{(\mathbf{1})}$.

De acordo com a doutrina e a jurisprudência estabelecidas nos princípios da responsabilidade civil médica, o profissional de saúde poderá ser responsabilizado quando agir com culpa, no sentido amplo, não somente pelo que fez, mas também, pelo que deixou de fazer ou pelo que informou ou deixou de informar.

1. Mestre em Medicina, Coordenador da Câmara Técnica de Medicina Legal do Conselho Regional de Medicina do Estado do Rio de Janeiro, Perito-Legista do Instituto Médico Legal Afrânio Peixoto - IML, Perito Médico Judicial, Rio de Janeiro, RJ, Brasil.

2. Doutor, Professor Adjunto do Departamento de Radiologia, Chefe da Seção de Diagnóstico por Imagem do Instituto de Ginecologia da Universidade Federal do Rio de Janeiro (UFRJ), Coordenador da Câmara Técnica de Radiologia do Conselho Regional de Medicina do Estado do Rio de Janeiro, Rio de Janeiro, RJ, Brasil.

3. Doutora em Educação, Pós-Doutorado na área de Psicologia Social, Professora de Didática da Universidade Federal Fluminense (UFF), Niterói, RJ, Titular da Área de Ensino-Aprendizagem da Universidade do Estado do Rio de Janeiro (UERJ), Rio de Janeiro, RJ, Brasil.

Endereço para correspondência: Dr. Luiz Carlos Prestes Jr. Rua Visconde de Ouro Preto, 79, ap. 502, Botafogo. Rio de Janeiro, RJ, Brasil, 22250-180. E-mail: luizprestesjr@gmail.com
A descrição dos problemas levantados nas ações judiciais a partir dos relatos dos próprios pacientes revela ampla variedade de queixas que geram as situações de conflito: a letra ininteligível do médico numa receita de medicamento, problemas ou complicações oriundas de intervenções cirúrgicas, passando por laudos de exames de conteúdo vago ou lacônico com diagnósticos equivocados, ressaltando-se que, na maioria dos casos, há alegação de informações inexistentes ou insuficientes sobre o tratamento.

Não há dados estatísticos oficiais sobre o número de processos envolvendo erro médico no Brasil. Entretanto, existe um consenso, no meio jurídico, de que há um significativo aumento no número de novas ações. Estima-se hoje que exista cerca de 10.000 processos tramitando nos tribunais contra médicos, em sua maioria arguindo responsabilidade civil do profissional ${ }^{(2)}$.

$\mathrm{O}$ número de processos envolvendo ações contra médicos enquadra-se dentro do perfil dos países em desenvolvimento. O Brasil, mesmo sem dados estatísticos oficiais, registra um número de processos abaixo daqueles que ocorrem em países desenvolvidos, mas acima dos países menos desenvolvidos.

Outro fator que influencia, sobremaneira, o aumento de tais demandas é o próprio crescimento populacional, mercê do aprimoramento instrucional e da facilidade de acesso às fontes de informação.

A mídia - escrita, falada e televisada -, em inúmeras ocasiões tem prestado um desserviço social, pois, visando ao lucro jornalístico e sensacionalista, não raro leviana, prejulga o médico, condenando-o de forma leiga, muito antes de uma apuração mais técnica e detalhada dos atos praticados. Com isso fere, moral e materialmente, médicos e pacientes, contribuindo para uma medicina defensiva e cada vez mais onerosa, longe de atender aos direitos constitucionais à saúde da sociedade.

O judiciário, em face do crescente número de ações, tem também o papel de desestimular as demandas infundadas, que alguns chamam de "loteria judicial", ou seja, uma forma descompromissada e irresponsável do paciente, desprovido de razões, tentar auferir algum lucro ou vantagem financeira, valendo-se dos inconvenientes que o processo acarreta ao médico, como altos custos judiciais, desgaste emocional, desmotivação pela especialidade e muitas vezes pela profissão, bem como sensação de impotência e injustiça.

O crescente incentivo e apelo democrático à chamada indústria do dano moral também acrescenta razões no incremento do processo de vitimização da sociedade.

A criação do Código de Defesa do Consumidor foi a grande divisora de águas, permitindo às vítimas dos chamados "erros médicos" maior proteção por meio de mecanismos jurídicos, como a gratuidade de justiça, a inversão do ônus da prova, e da concessão de indenizações astronômicas por danos morais ${ }^{(3)}$.

A socialização da medicina e a constante necessidade de sobrevivência no mercado de trabalho fizeram da medicina a profissão que mais absorve os impactos das novas concepções sociais, tornando-se, ao mesmo tempo, uma profissão de altíssimo risco.

\section{O PROCESSO JUDICIAL NO CONTEXTO DO EXERCÍCIO PROFISSIONAL}

Aspecto de maior importância para o tema é a grande transformação do relacionamento médico-paciente ao longo dos anos. A saudosa relação quase fraternal, cultuada entre pacientes, médicos e familiares, praticamente desapareceu, dando 
lugar a uma relação impessoal, fria e essencialmente técnica.

O relacionamento distorcido, muitas vezes, por consultas rápidas, superficiais, sem um diálogo mais aprofundado, e sem a participação de pacientes e familiares nas decisões terapêuticas, propicia certamente a questionamentos que podem ser levados à justiça ${ }^{(4)}$.

Temos também a considerar que hoje vivemos no mundo contemporâneo, momentos de marcantes transformações sociais e de valores. A influência da biotecnologia determina uma maior expectativa de cura das doenças, mas também predispõe a inúmeros e inevitáveis riscos.

O médico não pode ficar de fora desse contexto e das mudanças de paradigmas.

A sociedade reage com naturalidade quando o profissional médico atinge o sucesso da cura, com o tratamento instituído. Todavia, quando as expectativas não se concretizam e o êxito não é alcançado, o médico é execrado e presumidamente culpado, sujeito às mazelas dos processos judiciais.

$\mathrm{O}$ enorme arsenal tecnológico que o imaginologista dispõe, cada vez menos invasivo, facilita muito, sob o ponto de vista técnico, a abordagem do doente, mas por outro lado, afasta ou simplesmente prejudica a relação médico-paciente.

Um dos grandes avanços foi, sem dúvida, a ultrassonografia, uma modalidade de imagem realmente não invasiva, desaparecendo o risco de dano para o paciente.

No entanto, constitui um exame de imagem essencialmente operador-dependente e, sendo assim, requer treinamento e experiência do operador para sua correta interpretação.

\section{O ERRO DIAGNÓSTICO}

A falha no diagnóstico radiológico ("missed" radiographic diagnosis) é responsável por $70 \%$ dos processos envolvendo radiologistas nos Estados Unidos. Cabe, entretanto, diferenciar se tal falha se deu por negligência, imperícia ou imprudência, que, na maioria das vezes, torna árdua a tarefa para os peritos nomeados.

Alguns dos chamados "erros diagnósticos" estão relacionados à interpretação equivocada do profissional, seja pela falta de conhecimento, seja pela conclusão ina- dequada, ou ainda pela má escolha da técnica empregada ${ }^{(5)}$.

$\mathrm{Na}$ experiência adquirida ao longo dos anos, na análise médico-legal em processos de responsabilidade médica, foram também observadas falhas oriundas da identificação ou percepção das lesões, muitas vezes diminutas ou mal definidas.

Considerando a análise desses parâmetros, não se pode deixar de considerar a má qualidade dos equipamentos, a falta de manutenção, principalmente no interior dos Estados, em que os investimentos não contemplam o avanço tecnológico.

A obsolescência é patente na maioria das clínicas e hospitais de pequeno porte nos interiores desse imenso país. Sempre que um aparelho novo é lançado, o equipamento anterior é substituído e vendido por preços "módicos" às prefeituras e nosocômios de menor porte.

Vale ressaltar que tal prática é muito comum envolvendo mamógrafos. A não visualização de lesões nas imagens produzidas ou sua má interpretação podem gerar consequências graves para a paciente.

A mamografia é hoje o principal método de rastreamento do câncer de mama, portanto, é um exame de grande importância para a mulher e pode suscitar demandas judiciais de grande monta, quando não interpretado corretamente.

Com certa frequência são observadas, em processos de responsabilidade médica, condutas envolvendo falhas no diagnóstico de imagens "suspeitas" ou ainda a ocorrência de falso-negativos, que podem retardar o início do tratamento.

Algumas ações são de grande importância para evitar tais demandas, como a participação no Programa de Controle de Qualidade da Mamografia, gerenciado pelo Colégio Brasileiro de Radiologia e Diagnóstico por Imagem, e ainda a padronização do critério BI-RADS, amplamente utilizado $^{(6)}$. A integração com o médico assistente é sempre recomendável para uma abordagem multidisciplinar ao paciente.

Outro aspecto de suma importância, quando se analisa a questão médico-legal e pericial, é o laudo.

Documento é a expressão escrita de um fato, portanto, define exatamente aquele momento na interpretação da imagem. E é exatamente a análise deste documento e sua correlação com a clínica e com a imagem que será o objeto de atenção do perito.

Em exames de ultrassonografia obstétrica, isto se torna de extrema relevância, pois além da gestação, que constitui condição dinâmica em constantes transformações, existem fatores que podem diretamente influenciar na interpretação, como posição fetal e presença de imagens que podem dificultar a visualização dos parâmetros principais. Nas demandas judiciais envolvendo exames de ultrassonografia, a maioria dos exames questionados é de origem obstétrica. No caso de análise de biometria fetal, se alguma deformação ou alteração de estruturas forem ou não visualizadas, estas devem ser detalhadamente descritas e, se possível, documentadas por fotografia. Importante ressaltar que todo método de imagem tem limitações. $\mathrm{O}$ exame morfológico fetal tem constituído para o aumento na demanda de ações na justiça.

Atenção especial deve ser dada na correta correlação entre o laudo e o paciente que realizou o exame. A "troca" de exames, uma vez caracterizada, pode ensejar a condenação do profissional responsável à indenização por danos morais e materiais, dependendo do dano a ser apurado.

O laudo, expressando todas as ações realizadas durante o exame, deve descrever a técnica empregada, os dados do paciente, a região examinada e a descrição dos achados, tudo de forma objetiva e abrangente $^{(7)}$.

Nos casos em que o imaginologista está convicto de sua interpretação, o laudo pode ser concluído de forma mais direta e objetiva.

Atenção especial deve ser dada na revisão do laudo, momento no qual equívocos podem ser corrigidos. Laudos padronizados com o intuito de agilizar o trabalho podem constituir causa de erro ao informar, por exemplo, "vesícula biliar de aspectos normais" em paciente colecistectomizado.

É importante asseverar que, sendo o exame de imagem, na maioria de suas indicações, de caráter complementar, fica implícito que complementar a investigação diagnóstica e sua correlação com os dados clínicos do paciente é imprescindível ${ }^{(8)}$.

Uma relação que jamais pode ser quebrada é entre o imaginologista e o médico assistente, seja na consulta de dados do 
paciente ou na discussão do caso, sobretudo naqueles que requeiram condutas mais urgentes. A indicação de cisto ovariano identificado em paciente assintomática, na menacme, "com características funcionais", deixa entrever conduta conservadora.

Não deve ser desprezada a opinião de outro colega da área da radiologia, nos casos mais complexos e de difícil interpretação.

Conforme citado, os avanços tecnológicos permitem uma maior precisão diagnóstica, entretanto, na radiologia intervencionista algumas situações podem gerar ações judiciais. Por ser um procedimento invasivo, a utilização de contrastes, agulhas, cateteres e outros dispositivos aumenta o risco para o paciente, e este deverá ser devidamente informado sobre a possibilidade de ocorrência de determinadas situações ou complicações decorrentes.

O dever de informação é de relevância na análise processual. Os magistrados costumam subsidiar sua interpretação na aplicação do Código de Defesa do Consumidor, visto que hoje o dever de informação ensejará que o paciente participe diretamente das decisões médicas, podendo, inclusive, recusar submeter-se a procedimento, desde que não haja situação emergencial ${ }^{(\mathbf{9 , 1 0})}$.

O consentimento informado poderá ajudar no cumprimento do dever de informação, permitindo a decisão conjunta do paciente, desde que confeccionado especificamente para cada procedimento, detalha- damente descrito, e perfeitamente entendido e autorizado pelo paciente ${ }^{(\mathbf{1 1}, \mathbf{1 2})}$.

Como se sabe, jamais irá evitar uma demanda judicial, mas irá comprovar a informação levada ao paciente, quando solicitada a realização da prova técnica.

Todos os serviços, clínicas ou hospitais que realizam procedimentos invasivos ou intervencionistas devem ter, para pronto emprego, instrumental completo e medicamentos para ressuscitação cardiorrespiratória. Se for o caso, um convênio ou linha direta com empresa de remoção em UTI móvel pode proporcionar segurança ao paciente, numa eventualidade. Tais ações vão assegurar, na visão jurídica, os cuidados e a responsabilidade que envolve a instituição em relação ao paciente.

Atenção especial deve ser atribuída ao ensino médico e a sua prática em hospitais ou maternidades universitários. Muito embora o médico residente tenha autonomia pelos seus atos profissionais, estes devem ser sempre supervisionados por um preceptor ou médico mais experiente. Os laudos, a análise de imagens, os procedimentos invasivos, as manobras e as decisões técnicas são de responsabilidade do preceptor, orientador, chefe do serviço ou, ainda, do diretor técnico da unidade.

Nos dias de hoje, dizer que existe uma receita para evitar um processo judicial é ledo engano.

O que se observa, tomando por base os inúmeros processos judiciais envolvendo os médicos e principalmente os imagino- logistas, são atitudes de caráter preventivo, que podem trazer ao processo provas irrefutáveis da boa conduta, da perfeita integração nas interpretações de imagem e conclusões apresentadas, assegurando a boa prática médica.

Medida altamente salutar seria a abordagem de temas de Direito Médico nos cursos de graduação em medicina que, de forma mais abrangente e completa, orientaria os futuros profissionais médicos, quanto às situações de ordem prática, ressaltando os aspectos jurídicos e éticos que envolvem o exercício profissional.

\section{REFERÊNCIAS}

1. Couto Filho AF, Pereira AP. A improcedência no suposto erro médico. Rio de Janeiro, RJ: Lumen Júris; 1999.

2. Matiello FZ. Responsabilidade civil do médico. Porto Alegre, RS: Sagra Luzzato; 2001.

3. Giostri HT. Erro médico - à luz da jurisprudência comentada. Curitiba, PR: Juruá Editora; 2004

4. Panasco WL. A responsabilidade civil, penal e ética dos médicos. Rio de Janeiro, RJ: Forense; 1984.

5. Armstrong P, Wastie M, Rockall A. Diagnóstico por imagem. Rio de Janeiro, RJ: Revinter, 2006.

6. Camargo Jr HSA. Diagnóstico por imagem da mama - uma abordagem integrada. Rio de Janeiro, RJ: Revinter; 2008.

7. Petroianu A. Ética, moral e deontologia médicas Rio de Janeiro, RJ: Guanabara Koogan; 2000.

8. Erkonen WE, Smith WL. Radiologia - bases fundamentos. Rio de Janeiro, RJ: Revinter; 2006

9. França GV. Comentários ao código de ética médica. Rio de Janeiro, RJ: Guanabara Koogan; 2003.

10. Kfouri Neto M. Culpa médica e ônus da prova São Paulo, SP: Revista dos Tribunais; 2002.

11. Sebastião J. Responsabilidade médica - civil, criminal e ética. Belo Horizonte, MG: DelRey; 2001.

12. Souza NTC. Responsabilidade civil e penal do médico. Campinas, SP: LZN Ed.; 2003. 